\title{
Spontaneous disappearance of common bile duct stones after the use of a new dumbbell-shaped, covered self-expandable metallic stent in a patient with benign biliary stricture
} \author{
and Hiromasa Ohira ${ }^{2}$ \\ ${ }^{1}$ Affiliation not available \\ ${ }^{2}$ Fukushima Medical University \\ ${ }^{3}$ Fukushima Medical University School of Medicine
}

Yuto Ishizaki ${ }^{1}$, Mitsuru Sugimoto ${ }^{2}$, Tadayuki Takagi², Rei Suzuki ${ }^{2}$, Naoki Konno ${ }^{2}$, Hiroyuki Asama ${ }^{2}$, Yuki Sato ${ }^{2}$, Hiroki Irie ${ }^{2}$, Yoshinori Okubo², Jun Nakamura ${ }^{2}$, Mika Takasumi $^{2}$, Minami Hashimoto ${ }^{2}$, Tsunetaka Kato ${ }^{2}$, Ryoichiro Kobashi ${ }^{3}$, Takuto Hikichi ${ }^{2}$,

January 20, 2021

\begin{abstract}
Endoscopic stone removal becomes challenging owing to a distal common bile duct stricture. A new dumbbell-shaped covered self-expanding metallic stent is efficient in removing the common bile duct stones with common bile duct strictures that occur due to chronic pancreatitis.

Spontaneous disappearance of common bile duct stones after the use of a new dumbbell-shaped, covered self-expandable metallic stent in a patient with benign biliary stricture

Yuto Ishizaki ${ }^{1}$, Mitsuru Sugimoto ${ }^{1}$, Tadayuki Takagi ${ }^{1}$, Rei Suzuki ${ }^{1}$, Naoki Konno ${ }^{1}$, Hiroyuki Asama ${ }^{1}$, Yuki Sato $^{1}$, Hiroki Irie ${ }^{1}$, Yoshinori Okubo ${ }^{1,2}$, Jun Nakamura ${ }^{1,2}$, Mika Takasumi ${ }^{1}$, Minami Hashimoto ${ }^{1,2}$, Tsunetaka Kato ${ }^{1,2}$, Ryoichiro Kobashi ${ }^{1}$, Takuto Hikichi ${ }^{1,2}$, and Hiromasa Ohira ${ }^{1}$

${ }^{1}$ Department of Gastroenterology, School of Medicine, Fukushima Medical University, Fukushima, Japan

${ }^{2}$ Department of Endoscopy, Fukushima Medical University Hospital, Fukushima, Japan
\end{abstract}

\section{Correspondence}

Mitsuru Sugimoto, Department of Gastroenterology, School of Medicine, Fukushima Medical University, 1 Hikarigaoka, Fukushima, 960-1295, Japan.

E-mail address:kita335@fmu.ac.jp

\section{Abstract}

Endoscopic stone removal becomes challenging owing to a distal common bile duct stricture. A new dumbbellshaped covered self-expanding metallic stent is efficient in removing the common bile duct stones with common bile duct strictures that occur due to chronic pancreatitis.

\section{KEYWORDS}

benign biliary stricture, chronic pancreatitis, common bile duct stones

\section{1 | INTRODUCTION}


Common bile duct (CBD) stones are, generally, a risk factor for cholangitis and therefore, should be removed. Surgical lithotomy or endoscopic lithotomy is the preferred treatment modality to treat CBD stones. Owing to its minimally invasive nature, endoscopic lithotomy has become the first choice of treatment.

CBD stones may prove challenging to remove by endoscopic lithotomy, especially in patients with a very large stone size, multiple stones packed closely, ${ }^{1-5}$ a history of digestive tract reconstruction, ${ }^{6,7}$ or a combination of these factors. In addition to the above mentioned factors, the presence of a CBD stricture also increases the difficulty of endoscopic lithotomy. ${ }^{8-10}$ If a distal CBD stricture is narrower than the diameter of the CBD stones, removing the stones becomes further complicated.

Herein, we report a case in which the CBD stones were difficult to remove due to a CBD stricture caused by chronic pancreatitis (CP) and therefore; were also difficult to treat by endoscopic lithotripsy. However, these stones were spontaneously removed using a covered self-expanding metallic stent (CSEMS).

\section{2 | CASE PRESENTATION}

A 65-year-old man was admitted to our hospital for a periodic medical examination for CP. He also underwent periodic imaging examinations during 10 years follow-up on the benign biliary stricture caused by CP. Magnetic resonance cholangiopancreatography (MRCP) conducted as a part of these examinations revealed multiple CBD stones (Figure 1a). Contrast-enhanced computed tomography performed 6 months before the MRCP did not reveal the CBD stones, but instead revealed gallbladder stones. It was presumed that the gallbladder stones had progressively moved to the CBD. Therefore, we performed an endoscopic therapy for the CBD stones.

An endoscopic cholangiography revealed a distal CBD stricture and four CBD stones. The shortest diameter of each of the four CBD stones $(6 \mathrm{~mm}, 5 \mathrm{~mm}, 4 \mathrm{~mm}$, and $3 \mathrm{~mm}$ ) was larger than the diameter of the distal CBD lumen (Figure 1b); therefore, the extraction of the stones was challenging. After endoscopic sphincterotomy (EST) (Figure 1c), we attempted to remove the CBD stones using a basket catheter, which is often used for the destruction of stones, too. However, the movement of the basket catheter was limited by the biliary stricture. Therefore, the basket catheter could only hold a small stone but could not extract them. The distal biliary duct was extremely narrow. Therefore, there was a possibility that either the placement of multiple biliary plastic stents would be difficult, or it would not sufficiently dilate the distal biliary stricture to remove the CBD stones. Additionally, no pancreatic atrophy was observed during imaging examinations. Considering the risk of injury to the pancreatic parenchyma, we did not perform dilatation with a balloon catheter. Taking into consideration all of the abovementioned factors, a CSEMS was placed to dilate the distal CBD stricture (Figure 1d-e). The CSEMS used in this case was BONASTENT M-intraductal $8 \mathrm{~mm}$ $7 \mathrm{~cm}$ (Standard Sci Tech, Seoul, Korea). The stent has a dumbbell shape, with an 8-mm diameter at both ends, and a $6-\mathrm{mm}$ diameter at the center (Figure 2). The distal tip of the stent was pushed out from the duodenum to prevent proximal stent migration. Owing to the flared tips of the BONASTENT M-intraductal, the risk of proximal migration of the stent is reduced. The diameter of the CSEMS $(8 \mathrm{~mm})$ was the same as the diameter of the CBD. The length of the distal biliary stricture was $3 \mathrm{~cm}$. A 7- or 6-cm-long stent had a mid-portion length of $2 \mathrm{~cm}$, which is the longest version of the BONASTENT M-intraductal available commercially. In this case, the superior portion of the distal biliary stricture was slightly narrow. Therefore, we selected a longer stent of 7-cm length. Additionally, a pancreatic stent was placed in the main pancreatic duct to prevent post-endoscopic retrograde cholangiopancreatography (ERCP) pancreatitis. ${ }^{11-19}$

A week after the first session, the second endoscopic cholangiography procedure was performed. We observed that all the CBD stones detected in the first session had disappeared spontaneously (Figure 3a). After the CSEMS was removed, the biliary sludge was removed using a balloon catheter (Figure 3b). Finally, it was confirmed that there were no CBD stones, and the stricture of the distal CBD had slightly improved (Figure $3 c)$.

Approximately a year after the CBD stones were removed using the CSEMS, no recurrence of the CBD stones was observed on the follow-up imaging at an outpatient clinic. 


\section{3 | DISCUSSION}

There are 3 reports in the literature on cases of CBD stones with distal CBD strictures that were treated using CSEMS (Table 1). However, two case series did not mention the details of the cases with CBD stones and distal CBD strictures. A case series by Cerefice et al. targeted cases with the CBD stones that were difficult to remove using conventional endoscopic methods. ${ }^{8}$ Another case series by García-Cano et al. targeted older patients who had difficulty tolerating endoscopic lithotripsy due to the long duration required by the procedure. ${ }^{10}$

A case report by Okabe et al. described a case of CBD stones and distal CBD stricture due to CP. ${ }^{9}$ In that case, the CBD stones remained in the biliary duct and the upper portion of the CSEMS, and the distal biliary stricture did not improve despite CSEMS placement for 14 days. On the contrary, the CBD stones had spontaneously disappeared in our case and, the distal biliary stricture had also slightly improved by the placement of the CSEMS for only 7 days. This observation indicates that the new CSEMS BONASTENT M-intraductal (Standard Sci Tech) has strong dilation ability. The stent's dumbbell shape was thought to slightly prevent stent migration and transmit dilation forces to the CBD stricture.

The CSEMS should be placed for a longer duration to avoid recurrence of the CBD stones. Although, CSEMS dilated the distal CBD stricture, the distal CBD remained thin (Fig. 3c). In the past reports, variations were seen in the duration and effectiveness of the CSEMS placement for CBD strictures secondary to CP. Cahen et al. reported six cases that received CSEMS for CBD stricture with CP. ${ }^{20}$ They reported the CSEMS removal time to be 3-6 months and that $66 \%$ of the CBD stricture showed improvement. Lalezari et al. reported a case with $\mathrm{CP}$ in which the CBD was dilated by CSEMS. ${ }^{21}$ In this report, the CSEMS was placed for 63 days, and the CBD stricture had improved. Haapamäki et al. had conducted a randomized controlled study on the effectiveness of multiple plastic stents versus the CSEMS in treating biliary stricture with CP. ${ }^{22}$ In this study, CSEMS was removed 6 months after randomization, and the two-year stricture-free success rate was $92 \%(24 / 26)$. Although, the targets were not CP patients alone, Park et al. raised the duration of CSEMS placement to [?] 120 days as a factor for CBD stricture resolution. ${ }^{23}$

However, complications such as migration and embedding have been reported when the CSEMS was left in place for a longer duration. ${ }^{10,20,23-25} \mathrm{~A}$ new dumbbell-shaped CSEMS is thought to be useful in preventing misregistration. The duodenal tip of the dumbbell shape can prevent the embedding and migration into the biliary tract superiorly and while the hilar tip can prevent duodenal migration. If the new dumbbell-shaped CSEMS migrates into the biliary tract superiorly, removing the stent is thought to be easier than removing other types of the CSEMSs, primarily because the dumbbell-shaped CSEMS becomes narrower by pulling a string that is attached at the duodenal tip (Figure 2). Park et al. described that migration of the CSEMS is a risk factor that prevents benign CBD stricture resolution. ${ }^{23}$ Therefore, the dumbbell shape is expected to prevent misregistration and dilate the CBD stricture effectively. In fact, in this case, the CBD stricture was slightly dilated after CSEMS placement for only 7 days.

In conclusion, the new dumbbell-shaped CSEMS is efficient in removing the CBD stones with CBD strictures that occur due to CP. The stent might have the potential to prevent positional displacement and contribute to improved CBD stricture.

\section{ACKNOWLEDGEMENTS}

We thank all the staff at the Department of Gastroenterology of Fukushima Medical University, the Department of Endoscopy of Fukushima Medical University Hospital, and the gastroenterology ward of Fukushima Medical University Hospital. We also thank Editage for providing English language revision.

\section{CONFLICTS OF INTEREST}

All authors declare that they have no conflicts of interest.

\section{AUTHOR CONTRIBUTIONS}


Y.I, M.S, T.T: wrote the paper. R.S, N.K, H.A, Y.S, H.I, Y.O, J.N, M.T, M.H, T.K, R.K, T.H: provided clinical advice. H.O: reviewed and wrote the paper.

\section{ORCID}

Mitsuru Sugimoto https://orcid.org/0000-0002-4223-613X

\section{REFERENCES}

1. Ersoz G, Tekesin O, Ozutemiz AO, Gunsar F. Biliary sphincterotomy plus dilation with a large balloon for bile duct stones that are difficult to extract.Gastrointest Endosc. Feb 2003;57(2):156-159.

2. Meine GC, Baron TH. Endoscopic papillary large-balloon dilation combined with endoscopic biliary sphincterotomy for the removal of bile duct stones (with video). Gastrointest Endosc. Nov 2011;74(5):11191126; quiz 1115 e1111-1115.

3. Garcia-Cano J, Arana LT, Ayllon CJ, et al. Biliary sphincterotomy dilation for the extraction of difficult common bile duct stones. Rev Esp Enferm Dig. Aug 2009;101(8):541-545.

4. Itoi T, Itokawa F, Sofuni A, et al. Endoscopic sphincterotomy combined with large balloon dilation can reduce the procedure time and fluoroscopy time for removal of large bile duct stones. Am J Gastroenterol. Mar 2009;104(3):560-565.

5. Kim HG, Cheon YK, Cho YD, et al. Small sphincterotomy combined with endoscopic papillary large balloon dilation versus sphincterotomy. World J Gastroenterol.Sep 14 2009;15(34):4298-4304.

6. Park TY, Bang CS, Choi SH, et al. Forward-viewing endoscope for ERCP in patients with Billroth II gastrectomy: a systematic review and meta-analysis. Surg Endosc.Nov 2018;32(11):4598-4613.

7. Itoi T, Ishii K, Sofuni A, et al. Single-balloon enteroscopy-assisted ERCP in patients with Billroth II gastrectomy or Roux-en-Y anastomosis (with video). Am J Gastroenterol. Jan 2010;105(1):93-99.

8. Cerefice M, Sauer B, Javaid M, et al. Complex biliary stones: treatment with removable self-expandable metal stents: a new approach (with videos).Gastrointest Endosc. Sep 2011;74(3):520-526.

9. Okabe Y, Ishida Y, Sasaki Y, Ushijima T, Sugiyama G, Tsuruta O. Use of a partially covered selfexpandable metallic stent to treat a biliary stricture secondary to chronic pancreatitis complicated by recurrent cholangitis: a case report. Dig Endosc. May 2012;24 Suppl 1:55-58.

10. Garcia-Cano J, Reyes-Guevara AK, Martinez-Perez T, et al. Fully covered self-expanding metal stents in the management of difficult common bile duct stones.Rev Esp Enferm Dig. Jan 2013;105(1):7-12.

11. Singh P, Das A, Isenberg G, et al. Does prophylactic pancreatic stent placement reduce the risk of postERCP acute pancreatitis? A meta-analysis of controlled trials. Gastrointest Endosc. Oct 2004;60(4):544-550.

12. Mazaki T, Masuda H, Takayama T. Prophylactic pancreatic stent placement and post-ERCP pancreatitis: a systematic review and meta-analysis. Endoscopy.Oct 2010;42(10):842-853.

13. Choudhary A, Bechtold ML, Arif M, et al. Pancreatic stents for prophylaxis against post-ERCP pancreatitis: a meta-analysis and systematic review. Gastrointest Endosc. Feb 2011;73(2):275-282.

14. Mazaki T, Mado K, Masuda H, Shiono M. Prophylactic pancreatic stent placement and post-ERCP pancreatitis: an updated meta-analysis. J Gastroenterol. Feb 2014;49(2):343-355.

15. Shi QQ, Ning XY, Zhan LL, Tang GD, Lv XP. Placement of prophylactic pancreatic stents to prevent post-endoscopic retrograde cholangiopancreatography pancreatitis in high-risk patients: a meta-analysis. World J Gastroenterol.Jun 14 2014;20(22):7040-7048.

16. Fan JH, Qian JB, Wang YM, Shi RH, Zhao CJ. Updated meta-analysis of pancreatic stent placement in preventing post-endoscopic retrograde cholangiopancreatography pancreatitis. World J Gastroenterol. Jun 28 2015;21(24):7577-7583. 
17. Sugimoto M, Takagi T, Suzuki R, et al. Pancreatic stents to prevent post-endoscopic retrograde cholangiopancreatography pancreatitis: A meta-analysis. World J Metaanal. 2019;7(5):249-258.

18. Sugimoto M, Takagi T, Suzuki R, et al. Pancreatic stents for the prevention of post-endoscopic retrograde cholangiopancreatography pancreatitis should be inserted up to the pancreatic body or tail. World $J$ Gastroenterol. Jun 14 2018;24(22):2392-2399.

19. Sugimoto M, Takagi T, Suzuki R, et al. Prevention of post-endoscopic retrograde cholangiopancreatography pancreatitis using pancreatic stents: A review of efficacy, diameter and length. World $J$ Metaanal.2019;7(6):259-268.

20. Cahen DL, Rauws EA, Gouma DJ, Fockens P, Bruno MJ. Removable fully covered self-expandable metal stents in the treatment of common bile duct strictures due to chronic pancreatitis: a case series. Endoscopy. Aug 2008;40(8):697-700.

21. Lalezari D, Singh I, Reicher S, Eysselein VE. Evaluation of fully covered self-expanding metal stents in benign biliary strictures and bile leaks. World J Gastrointest Endosc. Jul 16 2013;5(7):332-339.

22. Haapamaki C, Kylanpaa L, Udd M, et al. Randomized multicenter study of multiple plastic stents vs. covered self-expandable metallic stent in the treatment of biliary stricture in chronic pancreatitis. Endoscopy. Jul 2015;47(7):605-610.

23. Park JS, Lee SS, Song TJ, et al. Long-term outcomes of covered self-expandable metal stents for treating benign biliary strictures. Endoscopy. May 2016;48(5):440-447.

24. Ryu CH, Kim MH, Lee SS, Park DH, Seo DW, Lee SK. Temporary placement of fully covered selfexpandable metal stents in benign biliary strictures. Korean J Gastroenterol. Jul 2013;62(1):49-54.

25. Cantu P, Hookey LC, Morales A, Le Moine O, Deviere J. The treatment of patients with symptomatic common bile duct stenosis secondary to chronic pancreatitis using partially covered metal stents: a pilot study. Endoscopy.Aug 2005;37(8):735-739.

Table 1 Past cases of CBD stones with distant CBD stricture treated using CSEMS

\begin{tabular}{|c|c|c|c|c|c|}
\hline $\begin{array}{l}\text { First author, } \\
\text { year }\end{array}$ & $\begin{array}{l}\text { Number of cases } \\
\text { with CBD } \\
\text { stricture }\end{array}$ & $\begin{array}{l}\text { Reason for CBD } \\
\text { stricture }\end{array}$ & CSEMS & $\begin{array}{l}\text { Duration of } \\
\text { CSEMS insertion }\end{array}$ & $\begin{array}{l}\text { All stone } \\
\text { removal }\end{array}$ \\
\hline $\begin{array}{l}\text { Cerefice et al., } \\
2011^{8}\end{array}$ & 5 & NA & $\begin{array}{l}\text { Wallstent, or } \\
\text { Viabil }\end{array}$ & $\begin{array}{l}\text { NA in patients } \\
\text { with distant } \\
\text { CBD stricture }\end{array}$ & $\begin{array}{l}\text { NA in patients } \\
\text { with distant } \\
\text { CBD stricture }\end{array}$ \\
\hline $\begin{array}{l}\text { Okabe et al., } \\
2012^{9}\end{array}$ & 1 & $\mathrm{CP}$ & Wall Flex & 2 weeks & $\begin{array}{l}\text { Achieved by } \\
\text { lithotripsy }\end{array}$ \\
\hline $\begin{array}{l}\text { García-Cano } \\
\text { et al., } 2013^{10}\end{array}$ & 11 & NA & Wall Flex & 90-389 days & $7 / 11$ \\
\hline This case & 1 & $\mathrm{CP}$ & $\begin{array}{l}\text { BONASTENT } \\
\text { M-intraductal }\end{array}$ & 7 days & $\begin{array}{l}\text { Spontaneously } \\
\text { disappeared }\end{array}$ \\
\hline
\end{tabular}

Abbreviations: CBD, common bile duct; CSEMS, covered self-expandable metallic stent; NA, not available; $\mathrm{CP}$, chronic pancreatitis.

\section{FIGURE LEGENDS}

FIGURE 1 The clinical course until the first endoscopic retrograde cholangiopancreatography (ERCP). (A) Common bile duct (CBD) stones (arrow) were detected in Magnetic resonance cholangiopancreatography. (B) In addition to CBD stones (arrow), distal CBD stricture (arrow head) was observed by endoscopic cholangiography. (C) After cholangiography, endoscopic sphincterotomy was performed. (D, E) A covered 
self-expandable metallic stent was placed to dilate the distal CBD stricture after the pancreatic stent was inserted to prevent post-ERCP pancreatitis.

FIGURE 2 The covered self-expandable metallic stent (CSEMS) used in this case was the BONASTENT M-intraductal. The shape of the stent resembles a dumbbell. By pulling a string, the BONASTENT Mintraductal becomes narrower. Therefore, the CSEMS is easy to remove.

FIGURE 3 The findings of the second endoscopic cholangiography. (A) No common bile duct (CBD) stones were observed. (B) After the covered self-expandable metallic stent was removed, the biliary sludge was removed by a balloon catheter. c It was confirmed that the stricture of distal CBD was improved to some extent (arrow head).

\section{Figure 1}
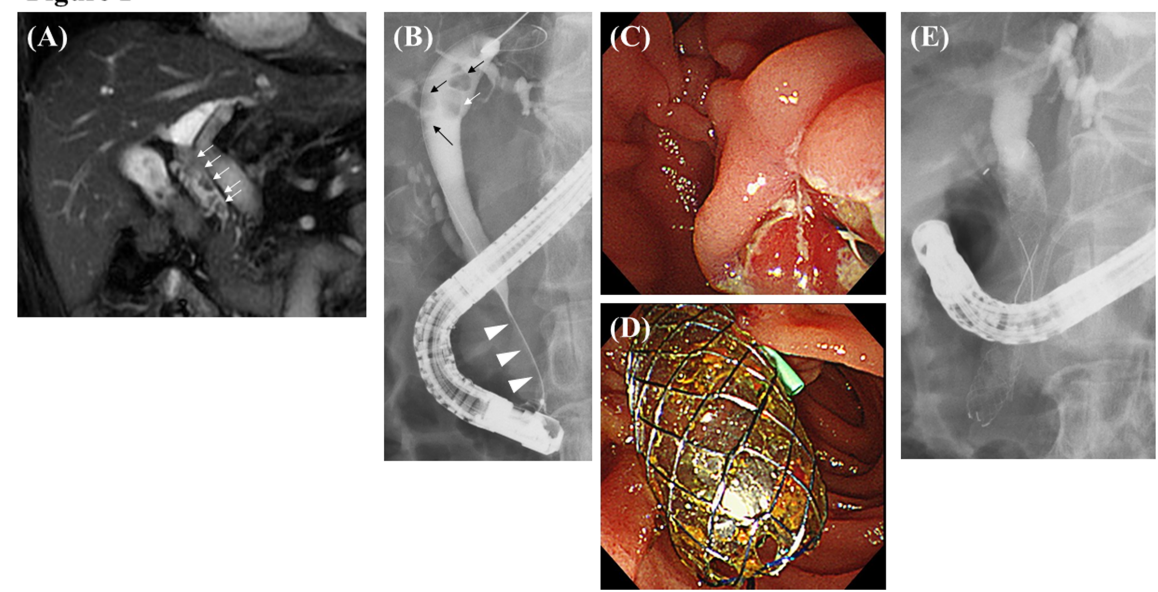

\section{Figure 2}

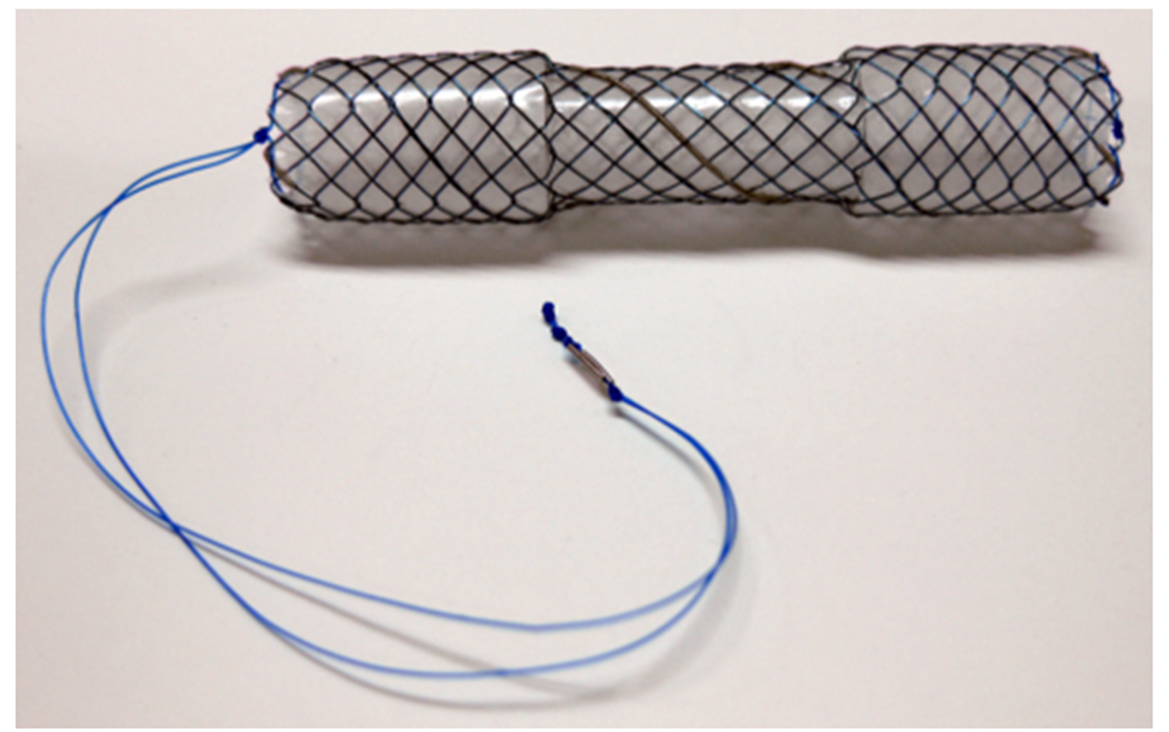


Figure 3
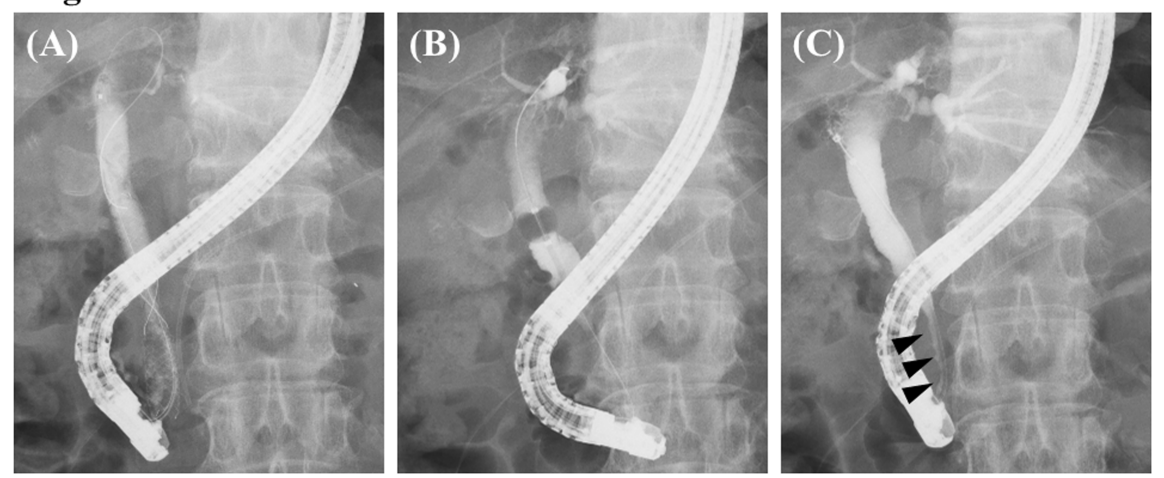